\title{
DISTINÇÃO ENTRE PRINCÍPIO, REGRA E "NORMA-OBJETIVO"
}

\author{
Carlos Silveira Noronha*
}

GENERALIDADES

CONCEITUAIS ENTRE DIREITO E ECONOMIA

Retroagem às primeiras manifestações do mundo científico as relações entre a Economia, como ciência explicativa, e o Direito, como ciência normativa, como de resto, a Economia e o Direito as têm com outras províncias do complexo científico.

A pardesses inter-relacionamentos de ordem geral, pode-se constatar que é a partir da transição do Estado liberal para o Estado social que o fenômeno econômico passou a interessar sobremodo à ordem jurídica, ou, mais exatamente, tal interação desabrochou com maior vigor desde o momento em que o Direito cogitou de regulamentar a atividade econômica. ${ }^{1}$

Convergem os autores em afirmar que é com o advento do Estado social, cujos albores na ordem política começam a se projetar no início do século $\mathrm{XX}$, notadamente com as constituições mexicana de 1917 e a de Weimar de 1919, que surge nas Cartas Políticas uma parte especial chamada "Ordem Econômica e Social". E, em tal sede, passaram as Constituições a conter um conjunto

\footnotetext{
* Professor titular da Faculdade de Direito da UFRGS, em nível de Pós-Graduação stricto sensu e da Faculdade de Direito das Faculdades Integradas São Judas Tadeu de Porto Alegre, em nível de graduação; Mestre e Doutor em Direito pela USP; Diretor da Revista da Faculdade de Direito da UFRGS, Diretor do Departamento de Direito Civil do Instituto dos Advogados do Rio Grande do Sul; advogado em Porto Alegre.
}

1 SOUZA, Washington Pelusio Abbino de-Direito Econômico, p. 14, Edição F.B.D.E., Belo Horizonte, 1975. 
de princípios e regras de organização da vida econômica, cujos conteúdos se afinam com os fins políticos do Estado. Exatamente nesse estágio de transformação do ente estatal, começa a oferecer-se campo propício para uma disciplina normativa moldada para regular a atividade econômica do Estado, que passou a denominar-se "Direito Econômico" e que paulatinamente conquista foros de cidadania através de proposições conceituais, enunciação de sua natureza, fixação de seu método e determinação do seu objeto.

Projeta-se, pois, tal disciplina jurídica, como uma iniciativa dualista resultante da síntese do liberalismo radical com a antítese do coletivismo extremado, segundo VIDIGAL ${ }^{2}$ ou na versão de COMPARATO, para quem "o Direito deixa-se penetrar de conteúdo econômico, ao mesmo tempo em que a Economia tornase sempre mais administrativa ou regulamentada, isto é, jurídica. ${ }^{3}$

Antes de passar a uma conceituação do Direito Econômico, é mister se observe que essa disciplina jurídica abriga em seu conteúdo a expressão de uma determinada ideologia que se encontra inscrita no texto das constituições e que assume a categoria de "norma-objetivo", na versão de EROS GRAU. ${ }^{4}$

Assim, desponta tal disciplina normativa quando o papel do Estado se amplia para receber os influxos da atividade econômica, e isso se dá não mais como na visão marxista, que divisa no Direito simples reflexo da Economia, nem como ao sabor de uma visão kantiana-stammlerista, para a qual as duas disciplinas fundem-se em uma só unidade, sendo a primeira forma do conteúdo da segunda (v. EROS, Elementos, cit. p. 24), mas como predica REALE, para quem Economia e Direito submetem-se a um regime de recíproca complementaridade, mediante um processo de interação dialética constante, de modo a "não se poder afirmar que a primeira cause o segundo, ou que o Direito seja "roupagem ideológica de uma dada forma de produção". 5

O brado de autonomia do Direito Econômico já se faz ecoar no seio das ciências jurídicas, partindo os

2 VIDIGAL, Geraldo de Camargo, Teoria Geral do Direito Econômico, p. 17, Edição RT, 1977.

3 COMPARATO, Fábio Conder. O Indispensável Direito Econômico, In: Ensaios e Pareceres de Direito Empresarial, p. 458, Ed. RT, 1978.

4 GRAU, Eros Roberto. Elementos de Direito Econômico, p. 23, Ed. RT, 1981.

5 REALE, Miguel. Lições Preliminares de Direito, p. 21, Ed. Saraiva, 1993. 
doutrinadores, que desde alguns anos para cá $o$ acolhem, para oferecer várias propostas de conceituação do mesmo Destarte, "Direito Econômico é a disciplina jurídica de atividades desenvolvidas nos mercados, visando a organizá-los sob a inspiração dominante do interesse social" (VIDIGAL, ob. cit. $n^{\circ} 41$, p. 44). Para o Prof. WASHINGTON, "Direito Econômico é o ramo do Direito que tem por objeto a regulamentação da política econômica e por sujeito o agente que dela participe. Como tal, é um conjunto de normas de conteúdo econômico que assegura a defesa e a harmonia dos interesses individuais e coletivos definidos pela ideologia adotada na ordem jurídica. Para tanto, utiliza-se do princípio da economicidade" (ob. cit., p. 7). Por fim, o Professor EROS conceitua-o como "o sistema normativo voltado à ordenação do processo econômico, mediante a regulação, sob o ponto de vista macrojurídico, da atividade econômica, de sorte a definir uma disciplina destinada à efetivação da política econômica estatal" (ob. cit. p. 31).
Em tais conceitos, delineiam-se sinteticamente o objeto do Direito Econômico no complexo do Direito Positivo pátrio e o caráter diferenciado das normas que o regulam e o delimitam.

\section{PRINCÍPIOS E REGRAS JURÍDICAS}

$\mathrm{O}$ ordenamento jurídico estatal não é integrado exclusivamente por regras jurídicas. Outra categoria normativa desempenha papel preponderante e definitivo no processo de inteligência e aplicação do Direito: são os princípios jurídicos ou princípios do Direito, conceituados sinteticamente na visão de léxico francês, "como regras, palavras ou construções que servem de base ao Direito como fontes de sua criação, aplicação ou interpretação (JERZY WROBLEWSKI. ${ }^{6}$ Outro autor francês, de nomeada, coloca em relevo os princípios jurídicos nos seguintes termos: "Les principes empruntent'une partie de leur majesté ou mystère que les entoure". ${ }^{7}$

6 WROBLEWSKI, Jersy. Dicionnaire Encyclopedique de Théorie et Sociologie du Droit, p. 317, apud EROS ROBERTO GRAU, A Ordem Econômica na Constituição de

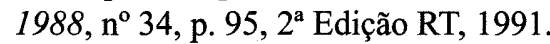

7 BOULANGER, Jean. Principes Généraux Du Droit et Droit Positif, In: Droit Privé Français au Milieu $d u X X^{o}$ Siècle (Etudes Offertes a Georges Ripert), LGDJ, Paris, 1950. 
O mesmo J. BOULANGER refere o conceito religioso, sobre princípios, de DOMAT, com base no direito natural, e os de PIANIOL e de CAPITANT, com fulcro no direito laico, especialmente no direito civil, para concluir que essas versões de tendência teocrática, e bem assim de ordem filosófica e de ordem laica, ainda que importantes para a compreensão dessa categoria normativa, mostram-se insuficientes para chegar-se a uma noção integral sobre "princípios jurídicos", porque estes ligam-se e se encartam na ordem jurídica positiva e aos mesmos se apela como instrumentos elucidadores e simplificadores da inteligência e aplicação das regras jurídicas (ob. cit., p. 53-54).

Cuida-se, pois, de princípios positivos do Direito, isto é, de princípios jurídicos que constituem normas jurídicas ou princípios jurídicos positivados, na expressão de EROS ROBERTO GRAU. Há, ainda, os princípios gerais do Direito, que embora não enunciados em normas jurídicas explícitas, são muitas vezes tomados pelo intérprete ou pelo aplicador do Direito, para a definição de determinadas soluções e decisões jurídicas. São aqueles princípios descobertos no ordenamento positivo que, mercê de sua consideração decisiva para a definição de determinadas soluções jurídicas, resultam positivados. Tais princípios encontram-se subjacentes em cada ordenamento jurídico, admitidos implicitamente no respectivo sistema, os quais, embora não enunciados em norma explícita, estão aí contemplados em estado de latência.

Por isso mesmo, não é de se pressupor que cada ordenamento jurídico venha a contemplar todos os princípios gerais do Direito. É certo que um determinado ordenamento jurídico - continua o Professor EROS - contemplará um determinado elenco deles; noutro sistema positivo poderá estar contemplado elenco diverso de princípios gerais do Direito. Exemplo de aplicação in concreto dessa última categoria é o relato feito pelo Professor EROS, extraído da obra "La lógica jurídica y la neva retórica", 105-108, de PERELMAN, a respeito de fato ocorrido na Bélgica, durante a primeira Guerra Mundial. Havendo sido o país ocupado pelo exército alemão e na impossibilidade de funcionamento da Câmara e do Senado, a legislação passou a ser editada unipessoalmente pelo Rei, que se encontrava no Havre, através de decretos-leis, com o que violavase o artigo 26 da Constituição da Nação, segundo o qual o poder de legislar, deveria exercitar-se pelo Rei, Câmara e Senado, conjuntamente. Terminado o conflito, os decretos-leis editados pelo Rei foram arguidos de ilegalidade, por afronta ao referido artigo 26 da Constituição belga. Porém, a Corte de cassação, amparada 
no artigo 130 daquela Lei Maior, que prescrevia: "a Constituição não pode ser suspensa, nem no seu todo, nem em parte"; concluiu que "na aplicação dos princípios constitucionais, o Rei, que durante a guerra era o único órgão do poder legislativo que conservara sua liberdade de ação, adotou as disposições com força de lei que a defesa do território e os interesses vitais da nação imperiosamente demandavam", e reconheceu legitimidade às referidas disposições legislativas editadas pelo Rei. ${ }^{8}$

Aí está um exemplo concreto, na ordem transnacional, de um princípio jurídico latente na ordem jurídica belga, que foi descoberto e aplicado pela Corte de Cassação daquele país, resultando positivado.

Mas, como salienta o provecto Professor das Arcadas, não se pode, a toda evidência, confundir princípios gerais do Direito, com princípios teoréticos elaborados pela Teoria Geral do Direito, em nível conceitual. E em prol dessa sua doutrina, transcreve o Professor EROS, exposição de DE DIEGO, em que aquele autor espanhol faz, de maneira primorosa, o destaque entre princípios positivados e princípios não positivados nos seguintes termos: "Principio en general (De primum capere o primum caput), significa cierta idea de precedencia y procedencia, por lo que se dijo que era el origen de alguna cosa o aquello de donde procedia. Principio de conocimiento, se decia en Ias escuelas, es aquello de que en el orden intelegible procede el conocimiento, como los axiomas respecto de Ias verdades de ellos deducidas. Principio de derecho es el pensamiento directivo que domina y sirve de base a la formación de las singulares disposiciones de Derecho de uma institución jurídica, de un Código o de todo un Derecho positivo. El princípio encarna el más alto sentido de una ley o institución de Derecho, el motivo determinante, Ia razón informadora del Derecho (ratio juris), aquella idea cardinal bajo Ia que se cobijan por la que se e explican los preceptos particulares, a tal punto, que éstos se halian com aquélia em la propia relación lógica que la consecuência al principio de donde se derivan. El principio no es la norma misma, pero se orienta hacia ella, y como se trata de princípios de Derecho que necessariamente dicen relación al obrar, ellos son normas supremas y fundamentales a las que em última instância debe subordinarse la conducta, em cuanto contienen el gérmen de aquellas reglas que

8 GRAU, Eros Roberto. A Ordem Econômica na Constituição de 1988, nº 33, p. 92-94, $2^{a}$ Edição RT, 1991. 
han de dominar las situaciones singulares em que socialmente nos hallemos colocados. Consecuencia del concepto dado de los princípios de derecho es que entre ellos puede establecerse una gradación, según su mayor o menor generalidad, desde el principio sumo que tiene razón de premier principio y domina toda la matéria de derecho, hasta aquel inferior y subordinado que disciplina una singular relación o instituclón jurídica. Muchos de estos principios aparecen consignados en las mismas leyes (ad exemplum, el del artículo 1902 del Código Civil españ்l), $\mathrm{y}$ claro es que entonces revisten la forma propia de normas jurídicas que por su función podrían denominarse definentes o declarativas. No hay necessídad de indicar que al respecto de estos últimos la determinación de su sentido y alcance es cuestión de interpretación; frente a ellos, la actividad del aplicador del Derecho ha de encauzarse principalmente por la via de Ia interpretación. La actividad del julgador frente a los otros principios no consignados expressamente en la ley, es otra y distinta". 9

De outro modo, a colocação de BOULANGER, anteriormente analisada, sugere desde logo a ideia de uma relação entre os princípios e as regras jurídicas. Fala a doutrina em regras jurídicas, mas também se refere frequentemente a princípios. São ambas, categorias necessárias à compleição inteira da ordem jurídica. Distingui-las, revela-se tarefa de capital importância, porque os princípios gozam de foros de cidadania jurídica e se constituem, como tais, elementos da própria ordem jurídica positiva.

Dessa assertiva, todavia, pode surgir uma objeção. Se a própria regra jurídica reveste-se da característica de generalidade e tal característica é também específica no princípio, ambos poderiam ser considerados sinônimos, porque gozam de um elemento identificativo que lhes é comum. Mas essa identidade vocabular da característica não deve servir de motivo para a confusão entre uma e outra categoria jurídica. É que existe entre um princípio e uma regra jurídica não só uma gradação de importância, mas também uma diferença de natureza, de tal modo que a generalidade de uma regra jurídica não deve ser entendida da mesma extensão que a generalidade de um

9 DE DIEGO, Clemente F. El Método en la aplicación del Derecho Civil, in Revista de Derecho Privado. T. III, PP. 292/293, Madrid, 1916, apud EROS ROBERTO GRAU, A Ordem Econômica na Constituição de 1988, n ${ }^{\circ}$ 43, pp. 117/118, $2^{\mathrm{a}}$ edição, RT, 1991. 
princípio, segundo BOULANGER (ob. cit., p. 55).

Com efeito, uma regra jurídica é geral no sentido que é estabelecida para um número indeterminado de atos ou fatos, mas no que pertine a certa relação ela é especial, porque não rege senão tais atos ou tais fatos, tendo em vista que ela é editada para reger uma situação jurídica determinada. Um princípio, ao contrário, sua generalidade comporta uma série indefinida de aplicações, em razão de ser mais amplo, no entendimento do citado autor. Um princípio, uma vez descoberto para reger determinada situação, pode ser reaplicado em outras situações concretas, sendo utilizável também para legitimar a aplicação analógica de um texto e, ainda, serve para estabelecer uma solução adequada na ausência de regra legal, o que leva a doutrina a considerá-lo indispensável elemento de fecundação da ordem jurídica positiva. Lembra o autor que "La ratio legis n'est pas autre chose qu'un príncipe", na versão de BOULANGER (ob. cit. pp. 56, 63 e 64).

Este autor, confirmando a antiga tese de CLEMENTE F. DE DIEGO, em 1916, entende que há também uma hierarquia interna entre os princípios, opinando, por exemplo, que os princípios de ordem técnica situamse numa posição de subordinação nessa escala hierárquica interior (BOULANGER, ob. cit., p. 72).

$\mathrm{E}$ remata este preclaro jurista francês: "Sem os princípios, tudo se desmorona, tudo se aniquila (...). $\mathrm{Na}$ falta de entusiasmo por ideias puras, o direito sucumbiria de interesse e não seria mais que um material empírico agindo ao sabor das circunstâncias, incapaz de assegurar a paz entre os homens "BOULANGER, ob. cit., p. 74).

E nessa perspectiva, há que se correlacionar o pensamento de RONALD DWORKIN. Este autor estabelece distinções entre regras (rules), princípios (principies) e o que chama diretrizes (policies). Além da classificação que faz das normas que compõem os sistemas jurídicos (em especial, o norteamericano), este autor observa que os profissionais do Direito fazem uso de pautas (standards), que não atuam como regras, mas funcionam como princípios e diretrizes (policies) ou outra espécie de pauta. Ao vocábulo princípio, propõe DWORKIN uso genérico, advertindo que entre princípios e diretrizes há que se estabelecer distinções, por exigência de maior precisão. ${ }^{10}$

10 DWORKIN, Ronald - Taking Rights Seriusly (Rules, principles and polices), p. 22, $5^{\mathrm{a}}$ impressão, Duckworth, Londres, 1987. 
Em seguida, faz o autor essa distinção, dizendo: " $\mathrm{Eu}$ chamo uma diretriz aquela espécie de norma que traça um objetivo a ser alcançado, em geral a melhoria de algum aspecto econômico, político ou social da comunidade (alguns objetivos são negativos, então estipulam que algum aspecto atual deve ser protegido contra mudança adversa). "Eu chamo um princípio uma pauta (standard) que deve ser observada, não porque ela vai viabilizar ou assegurar uma determinada situação econômica, política ou social considerada conveniente, mas porque ela é uma exigência de justiça, de imparcialidade ou de outra dimensão de moralidade". Exemplificando, refere que, nessa perspectiva, "a pauta (standard) de que os acidentes de automóveis devem diminuir é uma diretriz (policy) e a pauta (standard) de que nenhum homem pode tirar proveito de seu próprio delito são um princípio (DOWORKIN, ob. cit. p. 22).

Como se pode constatar, na doutrina de DWORKIN resulta evidente a proximidade entre as diretrizes (policies) e as normasobjetivo, de que adiante nos ocuparemos e que não escapou à costumeira agudez de percepção do Professor das Arcadas, EROS GRAU, como acima já se referiu. A propósito, há que se observar, também, que a ratio legis constitui um princípio para JEAN BOULANGER (ver ob. cit., p. 63).
Quanto ao discrime entre princípios e regras jurídicas, salienta DWORKIN que a sua posição é fruto de uma distinção lógica. E procurando elucidar o problema, diz textualmente: "Ambos os grupos de pautas (standards) legais apontam para decisões particulares acerca de obrigação particular e em circunstâncias particulares, mas elas diferem quanto ao caráter da direção seguida. As regras são aplicadas em estilo de tudo ou nada, de modo absoluto. Se ocorrem os fatos previstos numa regra e sendo ela válida, em qualquer caso deve ser aplicada". Exemplificando, se a regra dispõe que um testamento deve ter a presença de três testemunhas para ser válido, não há como tomar-se por válido se firmado somente por duas testemunhas (ver autor e ob. cit., p. 25).

Para a doutrina de DWORKIN, os princípios jurídicos atuam de modo diverso. Segundo a análise da doutrina desse autor, "mesmo aqueles que mais se assemelham às regras não se aplicam automaticamente $e$ necessariamente quando as condições previstas como suficientes para sua aplicação se manifestam". (...) "A circunstância de serem (os princípios) próprios a um determinado Direito não significa que esse Direito jamais autorize a sua desconsideração. Trabalhando com o princípio segundo o qual ninguém aproveita sua própria fraude (torpeza), DWORKIN aponta o fato de que, em 
determinados casos, o Direito não se opõe a que alguém obtenha proveito da fraude que praticou. O exemplo mais notável é o da posse indevida: aquele que penetrar em prédio alheio reiteradamente, durante largo período de tempo, poderá obter (...) o direito de cruzá-lo sempre que desejar", situação que caracteriza, para o Direito pátrio, a "passagem forçada", regulada no artigo 1.285 do Código Civil Brasileiro de 2002.

A segunda distinção feita por DWORKIN, entre princípios e regras jurídicas, é decorrente da primeira, ou seja, da distinção lógica. Funda-se essa segunda distinção na concepção de que os princípios têm uma dimensão de peso ou de importância que não ostentam as regras. Quando concorrem para a solução do caso vários princípios, deverá $o$ intérprete contrabalançar o peso de cada um deles, aplicando o de maior valoração. Isto não significa que o de menor peso ou importância deixe de viger no ordenamento jurídico respectivo, pelo simples fato de não haver sido aplicado.

As regras não possuem entre si dimensão de peso ou de importância, não se podendo afirmar que no interior do respectivo sistema normativo, uma regra transcenda de importância à outra, de modo que, no caso de conflito entre ambas, deve ,uma ser aplicada, decaindo ou caducando a outra, por inválida (DWORKIN, ob. cit., pp. 26-27.

\section{AS NORMAS-OBJETIVO}

\section{a) Noção e evolução da "norma-objetivo"}

A primeira noção de normaobjetivo nasceu na União Soviética, com os ensaios de CHEBANOV, de GOLOUNSKI e de LAPTEV, publicados no início da década de 60. Ao lado de normas-regra, surgem, em especial na legislação pertinente à atividade econômica, as normas-objetivo, como disposições normativas de natureza diversa, a respeito das quais o legislador não enuncia regras de conduta, nem de organização, limitando-se a indicar os resultados concretos que devem ser alcançados pelos seus destinatários, refere o Professor da Faculdade do Largo de São Francisco. ${ }^{11}$

Tradicionalmente, distinguemse, entre as normas jurídicas, as normas de conduta e as normas de organização. Consideram-se normas de conduta aquelas "cujo objetivo imediato é disciplinar o

11 GRAU, Eros Roberto. Verbete "Norma-objetivo, In: Enciclopédia Saraiva do Direito, vol. 54, p. 442-445, Edição Saraiva, S. Paulo. 
comportamento dos indivíduos, ou as atividades dos grupos e entidades sociais em geral". Por outro lado, consideram-se normas de organização aquelas que "possuem um caráter instrumental, visando à estrutura e funcionamento de órgãos, ou à disciplina de processos técnicos de identificação, e aplicação de normas, a fim de assegurar uma convivência juridicamente ordenada". Está-se aí diante de uma classificação binômica das normas jurídicas, que as toma em. consideração segundo o seu conteúdo. ${ }^{12}$

Todavia, modernamente, a partir do momento em que o ente estatal deixou de ser Estado-ordenamento, como mero produtor de ordem, segurança e paz, para assumir o papel de Estado-social, como agente da transformação social e como conformador da economia, começam a surgir no direito positivo inúmeros exemplos de normas que não mais se dirigem exclusivamente a regular condutas ou a instrumentar a organização de órgãos e a disciplinar processos viabilizadores da atividade estatal, mas que se destinam a fixar determinados resultados concretos, incluídos nos escopos do 'Welfare state". Tais normas não se confundem nem com as definidoras de condutas ou comportamentos, nem com as que instrumentam o funcionamento de órgãos ou disciplinam processos de identificação e aplicação de outras disposições normativas, como ocorre com as normas de conduta e as de organização da classificação tradicional, mas que se destinam a fixar objetivos a serem perseguidos, deixando aos destinatários a busca dos estilos de comportamento e formas de organização necessários à persecução dos referidos fins. A esse novo tipo de normas, que passam a exercer no ordenamento jurídico papel semelhante ao das obrigações de resultado (e não o das de meio) na ordem civil, é que a doutrina da segunda metade do século passado dá a denominação de norma-objetivo.

Abandona-se, assim, a classificação binômica tradicional para alcançar-se uma classificação trinômica, nova, das normas jurídicas. ${ }^{13}$

A introdução na doutrina nacional, e bem assim a especificação e identificação dessa categoria normativa, é fruto da pesquisa e conhecida : argúcia do Professor EROS ROBERTO GRAU, que a expôs em sua tese de LivreDocência nas Arcadas, intitulada

12 REALE, Miguel. Lições Preliminares de Direito, p. 97, Edição Saraiva, 1993. 13 GRAU, Eros Roberto. Verbete "Norma-objetivo", In: Enciclopédia Saraiva do Direito, vol. 54, pp. 442-445, Edição Saraiva, São Paulo. 
"Planejamento Econômico e Regra Jurídica", publicada em 1978, sendo pelo mesmo desenvolvimento em várias publicações posteriores.

Para melhor explicitar e oferecer praticidade à sua doutrina sobre a atuação da norma-objetivo no complexo da ordem jurídica, traça o Prof. EROS uma linha analógica entre o Direito e o jogo de xadrez, dando dinamicidade à classificação trinômica das normas jurídicas. No jogo de xadrez divisam-se três tipos de normas que o regulam: a) as regras sobre ojogo(definem as especificações do tabuleiro), correspondendo às normas de organização do jogo; b) as regras do jogo (que estabelecem os comportamentos dos disputantes) e que são normas de conduta; e por fim, c) as regras sobre o fim do jogo (colocar o adversário em xeque), pertinentes às normas-objetivo. ${ }^{14}$

No que diz com a aplicação das normas-objetivo no direito pátrio, COMPARATO, diz que elas se destinam a regular "a busca da justiça social e a valorização do trabalho, condição da dignidade humana". ${ }^{15}$
Para o Professor EROS ROBERTO GRAU normas-objetivo são, dentre outras, as inscritas no texto do artigo $3^{\circ} \mathrm{da}$ Constituição de 1988; as contidas no texto do artigo 170 do mesmo Estatuto Político. Como exemplos no âmbito do direito privado, uma pesquisa mais aprofundada arrolará inúmeros casos, mas é certo que a regra do artigo 154 da Lei das Sociedades Anônimas, é um deles; também o artigo 30 da Lei da Reforma Bancária (Lei n 4595/64), que "estabelece os objetivos da Política do Conselho Monetário Nacional". Por fim, no concerto do Direito Internacional, encontram-se muitas normasobjetivo nas respectivas convenções, como é, v.g., o caso do artigo 189 do Tratado de 1957, da Comunidade Econômica Europeia. ${ }^{16}$

\section{b) Crítica à doutrina da "norma-objetivo"}

O primeiro argumento crítico que se poderia desfechar contra essa categoria de norma é a de que ela está despida de sanção e, como tal,

14 GRAU, Eros Roberto. Direito, Conceito e Normas Jurídicas, $\mathrm{n}^{\circ}$ 165, p. 150, Edição RT, 1988.

15 COMPARATO, Fábio Conder. O Poder de Controle da Sociedade Anônima, $\mathrm{n}^{\circ} 115$, p. 297, Edição Forense, 1983.

16 GRAU, Eros Roberto. Direito, Conceitos e Normas Jurídicas, ns. 173 a 175, p. 145-147, Edição RT, 1988. 
estaria sufocada pela corrente que inadmite a norma jurídica sem sanção. É de ver que, segundo BOBBIO, a sanção é elemento constitutivo do Direito, presente no ordenamento jurídico como um todo, de modo que a norma recebe a sanção pelo só fato de estar integrada ao sistema. Além disso, se a ausência de sanção fosse incompatível com a juridicidade da norma, haver-se-ia de negar caráter jurídico a grande número de normas do Direito Constitucional e a todo o Direito Internacional, situação que não se harmoniza com os princípios. Por fim argumenta-se, a sanção diz com a vigência e não com a eficácia da norma.

Uma segunda objeção à presença da norma-objetivo na ordem jurídica é a de que esta carece de eficácia. Tal carência desaparece, todavia, contanto que se estabeleça a distinção entre eficácia jurídica e eficácia social. Analisando ambas, assevera JOSÉ AFONSO DA SILVA que a eficácia social refere-se ao fato de ser a norma realmente obedecida e aplicada, mas a sua ausência não tem força para desqualificar juridicamente a norma. ${ }^{17}$

A terceira objeção é no sentido de identificar as normas-objetivo com as normas programáticas. Não há superposição entre ambas. As normas programáticas servem de instrumento para viabilizar tanto condutas ou comportamentos quanto os fins perseguidos pelas normasobjetivo, de tal modo que os dois conceitos coexistem e não se repelem, eis que colocados em níveis diversos. Além disso, ambas as noções estão sujeitas a critérios diversos. A noção de norma-objetivo prende-se ao critério do conteúdo; a de norma programática submete-se ao critério da eficácia. Por fim, a qualificação de norma programática é exclusiva das normas constitucionais, ao passo que a norma-objetivo pode proliferar na esfera infraconstitucional, argumenta EROS ROBERTO GRAU. ${ }^{18}$

A vida autônoma da normaobjetivo no complexo do sistema normativo não pode deixar dúvidas ao analista de sua natureza. Em primeiro lugar, há que se verificar tratar-se de norma que contém, como as outras elencadas pela teoria geral, um comando abstrato e geral, que se mostra universal em relação à ação que define e também universal em relação ao seu destinatário. ${ }^{19}$

17 SILVA, José Afonso da. Aplicabilidade das Normas Constitucionais, p. 57-58, Edição RT, 1968.

18 GRAU, Eros Roberto. Direito, conceitos e Normas Juridicas, cits. ns. 175-180, p. 147-151.

19 GRAU, Eros Roberto. Lei do Plano, in Revista de Direito Público, ns. 53-54, ano XIII, p. 321. 
Reveste-se a norma-objetivo da característica da heteronomia comum a normas jurídicas, a que KANT recorre para estabelecer o discrime entre estas e a norma moral. Dotada de validade objetiva e transpessoal, por estar colocada acima das pretensões dos sujeitos da relação administração-administrado, mantém a estrutura de um querer geral, irredutível ao querer particular de qualquer dos sujeitos, segundo REALE.$^{20}$ De outro modo, fixadas as diretrizes e prioridades, não restam ao setor público outras alternativas a perseguir senão as correspondentes àquelas fixadas originariamente. Vale dizer, devem ser perseguidas essas diretrizes e prioridades, segundo a vontade ou, mesmo, contra a vontade do ente público, realizando-se em tal perspectiva, a heteronomia da norma-objetivo, argumenta o Professor EROS. ${ }^{21}$

Por fim, está essa categoria de norma dotada também da bilateralidade atributiva que, na doutrina de MIGUEL REALE, exorna os sistemas normativos. Ao conceituá-la, diz o jusfilósofo das
Arcadas: "Bilateralidade atributiva é o nexo objetivo que põe em relação dois ou mais sujeitos, discriminandolhes esferas autônomas de ser e de agir, conferindo-lhes pretensões, que, podendo ser recíprocas ou não, se acham sempre providas da garantia decorrente da objetividade do enlace"22, ou, como mais sucintamente expressou-a o jusfilósofo em outra oportunidade: "é uma proporção intersubjetiva, em função da qual os sujeitos de uma relação ficam autorizados a pretender, exigir, ou a fazer garantidamente algo". $\mathrm{Na}$ realidade, a relação vincular que se cria entre o Estado e o súdito em razão das diretrizes ou prioridades por aquele fixadas em favor deste, tuteladas pela norma-objetivo conferem à mesma a bilateralidade atributiva essencial a toda regra jurídica.

Disso se pode concluir que a norma-objetivo insere-se como categoria nova, no complexo normativo do Estado, completando-o, e convivendo harmonicamente com as demais classes de normas, como integrante do trinômio normativo inicialmente referido.

20 REALE, Miguel. Lições, cit. p. 49.

21 GRAU, Eros Roberto. Lei do Plano, In: Revista de Direito Público, cit., ns. 53-54, Edição RT, São Paulo.

22 REALE, Miguel. Filosofia do Direito, vol. $2^{\circ}$, $\mathrm{n}^{\circ}$ 245, p. 586, Ed. Saraiva, 1962; Idem, Ações Preliminares de Direito, p. 51. 


\section{REFERÊNCIAS}

BOULANGER, Jean. "Principes Généraux du Droit et Droit Positif", In: Droit Privé Français au Milieu $d u X X^{o}$ Siècle (Études offertes a Geoges Ripert), Paris, LGDJ, 1950.

COMPARATO, Fábio Conder. "O indispensável Direito Econômico", In: Ensaios e Pareceres de Direito Empresarial, p. 458, Edição Forense, Rio, 1978.

DE DIEGO, Clemente F. "El método de la aplicación del Derecho Civil" In: Revista de Derecho Privado, Tomo III, pp. 292/293, Madrid, 1916.

DWORKIN, Ronald. Taking Rights Seriously, (Rules, principles and policies), $5^{\mathrm{a}}$ impressão, Duckworth, Londres, 1987.

GRAU, Eros Roberto. "Planejamento Econômico e Regra Jurídica", tese de Livre-Docência nas Arcadas, Edição RT, São Paulo, 1978.

"Lei do Plano", In: Revista de Direito Público, p. 315 e segs., Ano XIII - janeiro/junho - 1980, ns. 53/54, Edição RT, São Paulo.

Verbete "Norma-objetivo", In: Enciclopédia Saraiva do Direito, vol. 54, pp. 442/445, São Paulo,
1980; Elementos de Direito Econômico, Edição RT, São Paulo, 1981; Direito, Conceito e Normas Jurídicas, Edição RT, São Paulo, 1988.

A Ordem Econômica na Constituição de 1988, Edição RT, São Paulo, 1991.

REALE, Miguel. Lições Preliminares de Direito, Edição Saraiva, São Paulo, 1993.

Filosofia do Direito, vol. $2^{\mathrm{a}}$, Ed. Saraiva, São Paulo, 1962.

SILVA, José Afonso da. Aplicabilidade das Normas Constitucionais, Edição RT, São Paulo, 1968.

SOUZA, Washington Pelusio Albino de. Direito Econômico, Edição F.B.D.E., Belo Horizonte, 1975. VIDIGAL, Geraldo de Camargo. Teoria Geral do Direito Econômico, Edição RT, São Paulo, 1977.

WROBLEWSKI, Jerzy. Dictionnaire Encyclopedique de Théorie et Sociologie du Droit, p. 317, apud Eros Roberto Grau, A Ordem Econômica na Constituição de 1988, no 34, p. 95, 2a Edição RT, São Paulo, 1991. 